\title{
RNA Affinity Chromatography
}

\author{
Nehal Thakor ${ }^{1}$ and Martin Holcik ${ }^{1,2}$ \\ ${ }^{1}$ Apoptosis Research Centre, Children's Hospital of Eastern Ontario \\ ${ }^{2}$ Department of Pediatrics, University of Ottawa \\ 1,2Canada
}

\section{Introduction}

Translation of eukaryotic mRNAs to proteins is the final step of gene expression which involves three steps; initiation, elongation and termination. Translation initiation is a rate limiting and highly regulated process, likely because it is more effective to control the very first step of protein translation instead of dealing with the consequences of aberrant protein translation. Most eukaryotic mRNAs harbor $5^{\prime} \mathrm{m}^{7} \mathrm{G}$ cap structure and 3' poly (A) tail. Typically, translation of eukaryotic mRNA starts with the association of eukaryotic intiation factor (eIF) 4F complex (eIF4E, eIF4G, eIF4A) with the $5^{\prime} \mathrm{m}^{7} \mathrm{G}$ cap structure via eIF4E. 43S initiation complex, comprising $40 \mathrm{~S}$ ribosomal subunit, ternary complex (eIF2-GTPtRNAiMet) and the multi-subunit initiation factor eIF3, is then recruited to mRNA via interaction of eIF3 with the scaffolding protein eIF4G. Subsequently, this pre-initiation complex is believed to scan the mRNA in the $5^{\prime}$ to $3^{\prime}$ direction until an initiation start codon is recognized. eIF2 delivers initiator tRNA into the peptidyl (P) site of the ribosome where initiation codon is situated. Following recruitment of initiator tRNA, eIF5 binds to the resulting $48 \mathrm{~S}$ initiation complex and induces GTPase activity of eIF2a. Initiation protein factors are released from the $48 \mathrm{~S}$ initiation complex upon GTP hydrolysis by eIF2a, and the 605 ribosome subunit joins the $40 \mathrm{~S}$ ribosome subunit to form $80 \mathrm{~S}$ initiation complex in a process that is aided by eIF5B. Elongation of polypeptide chain synthesis commences following $80 \mathrm{~S}$ initiation complex formation at AUG (for detail reviews see Gebauer \& Hentze, 2004; Holcik \& Sonenberg, 2005; Graber \& Holcik, 2007; King et al., 2010) (Figure 1).

During physiological or pathophysiological stress conditions the cap-dependent translation initiation is compromised either due to the proteolytic cleavage of initiation factors or changes in the phosphorylation status of the initiation factors and their binding partners (reviewed in King et al., 2010). A class of mRNAs harbouring Internal Ribosome Entry Site (IRES) can bypass the global attenuation of protein translation. IRESes are believed to directly recruit ribosome to the vicinity of start codon thus bypassing the need for capbinding and ribosome scanning. We and others have shown that the IRES mechanism is utilized preferentially during conditions when normal, cap-dependent translation initiation is attenuated and in fact represents a critical survival switch during oncogenesis (e.g. Holcik et al., 2000; Silvera \& Schneider, 2009). Translational control by internal initiation thus represents a novel and unique regulatory mechanism that is critical for cell survival. 


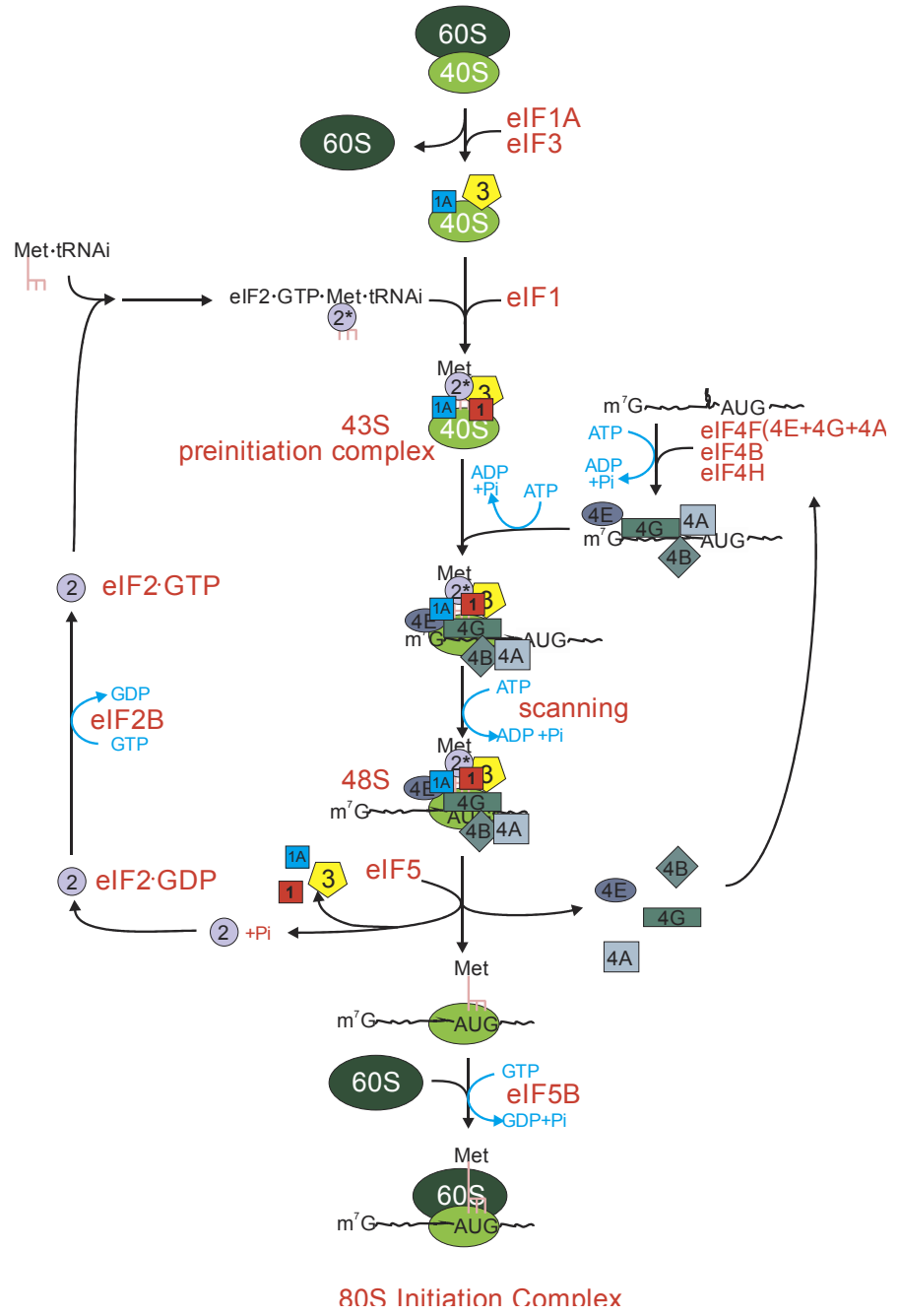

Only key initiation factors (eIFs) involved in the stepwise assembly of the $80 \mathrm{~S}$ initiation complex are shown. Binding of the eIF4 factors on the mRNA is thought to melt the secondary structure in the $5^{\prime}$ untranslated region and the unfolded mRNA is then capable of interacting with the 435 preinitiation complex. The $40 \mathrm{~S}$ ribosomal subunit, with associated initiation factors, is then thought to scan in the 3' direction until an AUG initiation codon in a favorable context is found and the $48 \mathrm{~S}$ initiation complex is formed. The recruitment of the $60 \mathrm{~S}$ ribosomal subunit to form the $80 \mathrm{~S}$ initiation complex completes the initiation step and protein synthesis continues with polypeptide elongation and termination steps (Adapted from Holcik \& Sonenberg, 2005).

Fig. 1. Schematic diagram of cap dependent translation initiation

A sizeable proportion of cellular mRNAs, perhaps as much as $10 \%$, has been shown to be translated by a cap-independent mechanism (Johannes \& Sarnow, 1998; Blais et al., 2004). It is likely that most of these mRNAs contain an IRES, as IRES-mediated translation is the only 
validated cap-independent translational mechanism described to date. IRES elements were initially discovered in picornaviruses, where they initiate translation of naturally uncapped viral RNAs (Pelletier \& Sonenberg, 1988). Cellular IRESes have been described in a small, but growing, number of mRNAs and often encode proteins that play key roles in cell growth and proliferation, differentiation and the regulation of apoptosis. Thus, we and others have proposed that the selective regulation of IRES-mediated translation is important for the regulation of cell death and survival. Indeed, the experimental data from many laboratories have now validated this hypothesis in a number of models (reviewed in Holcik \& Sonenberg, 2005; Braunstein et al., 2007; Silvera et al., 2010; Spriggs et al., 2010; Blagden \& Willis, 2011; Komar \& Hatzoglou, 2011). In contrast to cap-dependent translation, the translation of IRES-containing cellular mRNA is poorly understood and requires the activity of auxiliary RNA-binding proteins that function as IRES trans-acting factors (ITAFs). Exactly how ITAFs modulate IRES activity is not clear; ITAFs were suggested to act as adapter proteins which act as a bridge between the ribosome and mRNA (Mitchell et al., 2005), or as RNA chaperones which remodel mRNA into a conformation that permits ribosome recruitment (Yaman et al., 2003). We have been studying IRES-mediated translation of cellular mRNAs during stress using two anti-apoptotic proteins, $X$ chromosome-linked inhibitor of apoptosis (XIAP) and cellular inhibitor of apoptosis protein 1 (cIAP1), as model systems (Holcik et al., 1999; Graber et al., 2010; Riley et al., 2010; Thakor \& Holcik, 2011). To gain full understanding of the regulation and function of XIAP and cIAP1 IRESes, it was necessary to isolate and identify ITAFs which modulate IRES activity. To this end we have used several complementary approaches that are described in detail below.

\section{RNA-affinity chromatography}

RNA-affinity chromatography is relatively simple technique which facilitates isolation and characterization of various RNA binding proteins. Numerous strategies have been employed for RNA affinity chromatography using variety of affinity matrices which immobilize RNA to the solid support either covalently or non-covalently, and are briefly described below. While all strategies can be used to successfully isolate RNA-binding proteins, they all present distinct challenges that need to be considered when designing the experiments. Cyanogen bromide activated sepharose and adipic acid dihyrazide agarose are widely used to covalently immobilize RNA (Kaminski et al., 1995; Caputi et al., 1999; Copeland \& Driscoll, 1999; Sela-Brown et al., 2000; Hovhannisyan \& Carstens, 2009). In the first approach, random sites of RNA attach to the matrix and therefore not all RNA molecules may maintain a homogeneous conformation which limits the number of accessible protein binding sites. Furthermore, cyanogen bromide activated sepharose can non-specifically capture RNA from the cell lysates used for the affinity chromatography which results in isolation of unspecific proteins. The second approach requires oxidation of RNA at 3' end using sodium periodate which makes the process inconvenient.

The poly-A tailed RNA bound proteins can be isolated using poly-U sepharose which noncovalently immobilizes poly-A tailed RNA (Neupert et al., 1990; Siebel et al., 1994). This approach requires extensive processing of the cytoplasmic lysate, which is used for affinity chromatography, in order to remove endogenous poly-A tailed mRNAs which would otherwise compete for binding on poly-U sepharose. 
The RNA which contains recognition sequences for MS2 (bacteriophage coat protein) can be non-covalently attached to amylose beads via a recombinant chimeric protein MS2-MBP (maltose binding protein) (Zhou et al., 2002). In this approach, RNA attachment on the solid matrix depends on the affinity of MS2-MBP protein for the RNA and for the amylose beads. This approach is relatively expensive and inconvenient because it requires purification of recombinant MS2-MBP protein.

Aptamers are functional oligonucleotide sequences which bind non-covalently with high affinity and specificity to proteins, peptides and other small molecules (Tombelli et al., 2005; Ravelet et al., 2006; Hutanu \& Remcho, 2007; Peyrin, 2009). Non-covalent RNA attachment can be achieved by inserting aptamer sequences which specifically bind with streptomycin, so called StreptoTag, (Bachler et al., 1999) or streptavidin (Srisawat \& Engelke, 2001) immobilized on the solid matrix. If this approach is used, the aptamer specific for streptomycin or streptavidin needs to be inserted at the site where it is exposed to the solvent. If the aptamer insertion site falls along the length of RNA, then it limits protein binding sites.

The high affinity binding of biotin by avidin $\left(\mathrm{K}_{\mathrm{d}} \sim 10^{-15} \mathrm{M}\right)$ has made the biotin-avidin association an extremely powerful tool for affinity chromatography and a method of choice for many researchers (e.g. Rouault et al., 1989; Bayer \& Wilchek, 1990; Ruby et al., 1990; Gerbasi \& Link, 2007; Sharma, 2008). RNA can be biotinylated either at 5' end by enzymatic reaction or internally by using biotinylated nucleotides during in vitro transcription. The $5^{\prime}$ end biotinylated RNA is preferred over RNA carrying biotin substitutions along its length because internally tagged RNA can bind to the matrix using random sites which limits the protein binding sites. Therefore, we have used biotin-avidin RNA-affinity chromatography approach followed by mass-peptide fingerprinting to isolate and indentify ITAFs which modulate XIAP and cIAP1 IRES activities (Baird et al., 2007; Lewis et al., 2007; Graber et al., 2010; Durie et al., 2011). A general scheme for avidin-biotin RNA affinity chromatography is illustrated in Figure 2. First, in vitro transcribed IRES RNA is biotinylated at $5^{\prime}$ end and conjugated to the avidin-agarose beads which are then incubated with pre-cleared cytoplasmic lysate. After stringent washing, captured proteins are separated on SDS-PAGE and stained with SYPRO Ruby or Silver stains. Specific bands can then be excised and analyzed by MALDI-TOF mass spectrometry and peptide mass fingerprinting. Identity of the proteins can be further confirmed by Western blot analysis.

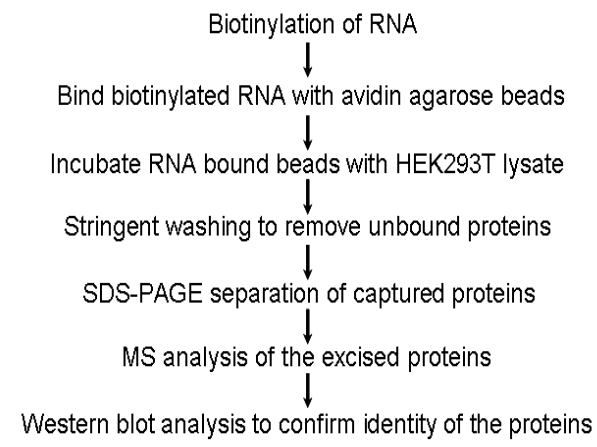

Fig. 2. Schematic diagram of avidin-biotin RNA affinity chromatography procedure 


\section{Avidin-biotin RNA affinity chromatography procedure}

\subsection{RNA biotinylation}

In vitro transcribe the RNA of interest using Megashortscript kit (Ambion, Austin, TX, USA) and biotinylate at $5^{\prime}$ end by enzymatic reaction using EndTag ${ }^{\mathrm{TM}}$ Nucleic Acid Labeling System (Vector Laboratories, Burlingame, CA) as illustrated in Figure 3. Carry out dephosphorylation of RNA by combining $1 \mu$ universal reaction buffer, 0.6 nmol RNA and $1 \mu \mathrm{l}$ alkaline phosphatase. Bring the final reaction volume to $10 \mu \mathrm{l}$ and incubate at $37^{\circ} \mathrm{C}$ for $30 \mathrm{~min}$. Subsequently, add $2 \mu \mathrm{l}$ universal reaction buffer, $1 \mu \mathrm{ATP} \gamma \mathrm{S}$ and $2 \mu \mathrm{T} \mathrm{T} 4$ polynucleotide kinase into the reaction. After bringing up the reaction volume to $20 \mu \mathrm{l}$, incubate the reaction further at $37^{\circ} \mathrm{C}$ for $30 \mathrm{~min}$. Mix biotin maleimide $(10 \mu \mathrm{l})$ with the reaction and incubate at $65^{\circ} \mathrm{C}$ for $45 \mathrm{~min}$. Mix water $(70 \mu \mathrm{l})$ and buffered phenol $(100 \mu \mathrm{l})$ (Sigma-Aldrich, Oakville, ON, Canada) with the reaction and vortex briefly. Centrifuge the tube at 13,000 RPM for $1 \mathrm{~min}$ at $4^{\circ} \mathrm{C}$ and collect the upper aqueous layer. To this aqueous fraction add $5 \mu \mathrm{l}$ precipitant and $263 \mu \mathrm{l}$ of $95 \%$ ethanol and precipitate RNA overnight at $20^{\circ} \mathrm{C}$. Next day centrifuge the tube at 13,000 RPM for 30 minutes at $4^{\circ} \mathrm{C}$ to obtain RNA pellet. Wash the pellet with $70 \%$ ethanol and dry it under vacuum. Resuspend the pellet in $20 \mu \mathrm{l}$ RNAse free water and store at $-80^{\circ} \mathrm{C}$ if necessary.
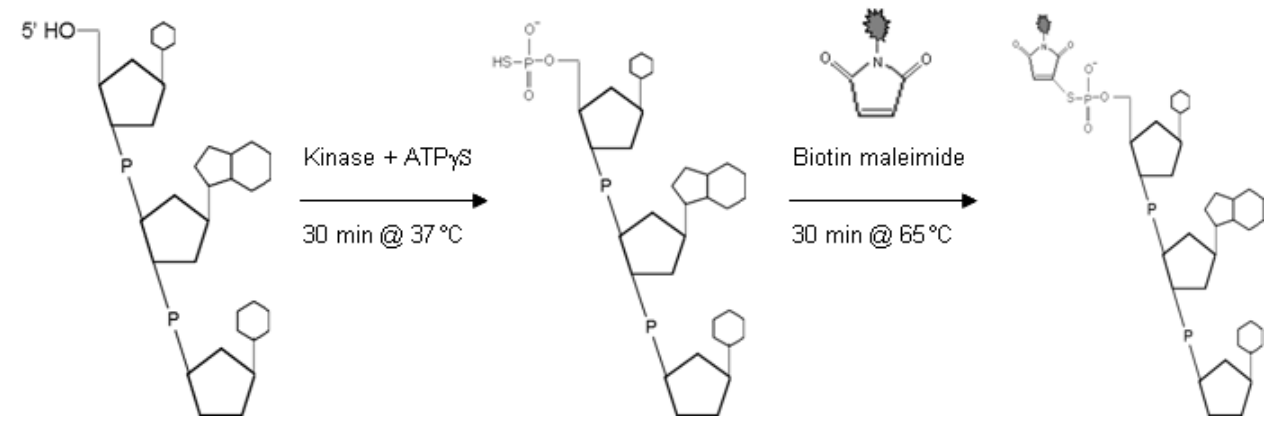

(Adapted from product manual, Vector Laboratories)

Fig. 3. Schematic outline of RNA biotinylation at 5' end

\subsection{Preparation of the cytoplasmic lysate}

The following procedure was used to isolate RNA binding proteins from HEK293 cells, but it can be applied to any other cell line. Grow cells to $\sim 80 \%$ confluency in five $10 \mathrm{~cm}$ plates and collect them in $15 \mathrm{ml}$ Falcon tube in phosphate buffered saline (PBS). Chill the cells on ice and centrifuge at $800 \mathrm{~g}$ for $5 \mathrm{~min}$ and collect the cell pellet. Wash the cell pellet two times with cold PBS and centrifuge at $800 \mathrm{~g}$ at $4^{\circ} \mathrm{C}$ for $5 \mathrm{~min}$. Resuspend the cells in $750 \mu \mathrm{l}$ of homogenization buffer (10 mM Tris- $\mathrm{HCl}(\mathrm{pH} 7.4), 1.5 \mathrm{mM} \mathrm{MgCl} 2,10 \mathrm{mM} \mathrm{KCl})$ containing $0.1 \mathrm{mM}$ phenylmethylsulfonyl fluoride (PMSF), $0.5 \mathrm{mM}$ dithiothretol (DTT) and $10 \mu \mathrm{g} / \mathrm{ml}$ leupeptin and lyse the cells by dounce-homogenizer (30 strokes, pestle ' $\mathrm{B}^{\prime}$ ). Centrifuge the lysate at $2,000 \mathrm{~g}$ at $4^{\circ} \mathrm{C}$ for $10 \mathrm{~min}$ to pellet nuclei. Centrifuge the lysate further at $10,000 \mathrm{~g}$ at $4^{\circ} \mathrm{C}$ for $15 \mathrm{~min}$ and collect the supernatant. Determine protein concentration of the lysate by Bradford's or other suitable protein assay. Bring the final concentrations of 
glycerol and $\mathrm{KCl}$ in the lysate to $5 \%$ (vol/vol) and $150 \mathrm{mM}$ respectively, if necessary store the lysate at $-80^{\circ} \mathrm{C}$.

\subsection{Pre-clearing of the cytoplasmic lysate}

Mix the cytoplasmic lysate ( $2 \mathrm{mg}$ ) with $20 \mu \mathrm{l}$ RNAsin (Promega, Madison, WI, USA) and 12 $\mu \mathrm{g}$ yeast tRNA (Sigma-Aldrich). Bring the final volume of the lysate to $825 \mu \mathrm{l}$ by binding buffer (10 mM Tris- $\mathrm{HCl}(\mathrm{pH} 7.4), 1.5 \mathrm{mM} \mathrm{MgCl}$, $150 \mathrm{mM} \mathrm{KCl}, 0.1 \mathrm{mM}$ PMSF, $0.5 \mathrm{mM}$ dithiothretol (DTT), $10 \mu \mathrm{g} / \mathrm{ml}$ leupeptin and 0.05\% NP-40). Mix the buffer-washed avidin agarose beads $(225 \mu \mathrm{l})$ (Sigma-Aldrich) with the cytoplasmic lysate and incubate at $4^{\circ} \mathrm{C}$ for 2 $\mathrm{h}$ on a rotator. Centrifuge the tube at $6,500 \mathrm{rpm}$ for $1 \mathrm{~min}$ to pellet the beads and collect the supernatant.

\subsection{Capturing RNA bound proteins on avidin agarose matrix}

Wash avidin agarose beads $(225 \mu \mathrm{l})$ with the binding buffer and combine them with $120 \mu \mathrm{g}$ $(0.24 \mathrm{nmol})$ of biotinylated RNA and incubate at $4^{\circ} \mathrm{C}$ for $2 \mathrm{~h}$ on a rotator. Centrifuge the beads at 6,500 rpm for $1 \mathrm{~min}$ and wash two times with $500 \mu \mathrm{l}$ binding buffer. Mix the RNAbound beads with $2 \mathrm{mg}$ of pre-cleared cytoplasmic lysate and incubate at room temperature (RT) on a rotator for $30 \mathrm{~min}$. Incubate the tube at $4^{\circ} \mathrm{C}$ for further $2 \mathrm{~h}$ on a rotator. Wash beads 5 times with binding buffer and finally boil with 1X SDS-PAGE loading buffer. Separate captured proteins on SDS-PAGE and stain with SYPRO Ruby stain (Genomic Solutions, Ann Arbor, MI). Excise specific bands from the gel and subject them to mass peptide fingerprinting. Alternatively, confirm the protein identity by Western blot analysis with suitable antibodies.

\subsection{Avidin-biotin RNA-affinity chromatography isolation of XIAP and cIAP1 IRES binding proteins}

To illustrate the utility of the above-described approach we have previously used the minimal functional XIAP IRES (-162 to +1 nt of $5^{\prime}$ UTR of XIAP) (Lewis et al., 2007) and cIAP1 IRES (-150 to +1 nt of 5' UTR of cIAP1) (Graber et al., 2010) elements to isolate and identify XIAP and cIAP1 ITAFs, respectively. When XIAP IRES RNA conjugated beads were used in an affinity pulldown, at least six distinct proteins were isolated (Figure 4A Lane \# 2) (Lewis et al., 2007). A control reaction using avidin-agarose beads alone did not yield any proteins (Figure 4A Lane \# 1) indicating that the proteins isolated with XIAP IRES RNA were specific. The mass peptide fingerprinting of p37 protein species captured on XIAP IRES RNA revealed that in fact p37 protein species is a mixture of hnRNPA1 and HuR (Figure 4B) (Lewis et al., 2007; Durie et al., 2011). The specificity of HuR and hnRNPA1 interaction with the XIAP IRES RNA was confirmed by Western blot analysis (Figure 4C) (Lewis et al., 2007; Durie et al., 2011). The protein species p52 and p44 were also subjected to mass peptide fingerprinting and were identified as La autoantigen (p52) and hnRNP C1/C2 (p44); both proteins were previously shown to interact with XIAP IRES RNA (Holcik \& Korneluk, 2000; Holcik et al., 2003). In addition, Western blot analysis of the RNA chromatography eluate using antibodies against candidate proteins Baird et. al. confirmed the presence of La autoantigen, hnRNP C1/C2 and PTB in the XIAP IRES RNA-protein complex (Baird et al., 2007) (Figure 4C). 


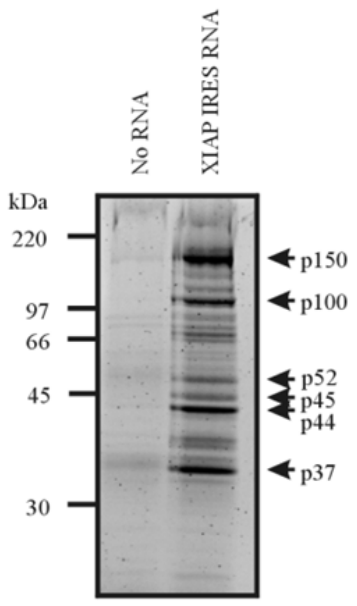

(a)

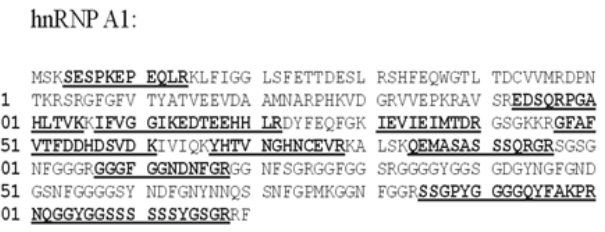

\section{HuR:}

MSNGYEDHMA EDCRGDIGRT NLIVNYLPQN MTQDELRSLF SSIGEVESAK 1 LIRDKVAGHS LGYGEVNYVT AKDAERATNT LNGLRLQSK: IKYSYARPSS 01 BVIKDANLYI SGLPRTMTOK DVEDMFSRFG RIINSEVLVD OTTGLSRGVA 151 FIREDKRSEA EEAIT'SENGH KPPGSSEPIA VIFAANPNQN KNVALLSOLY 201 HSPARRFGGP VHHQAQRERF SPNGVDHMSG LSGVNVPGNA SSGWCIFIYN 251 LGQDADEGIL WOMFGPFGAV TNVKVIRDFN TNKCKGEGEV TMTNYEEAAM 301 AIASLNGYRL GDKILQVSEK TNKSHK

(b)
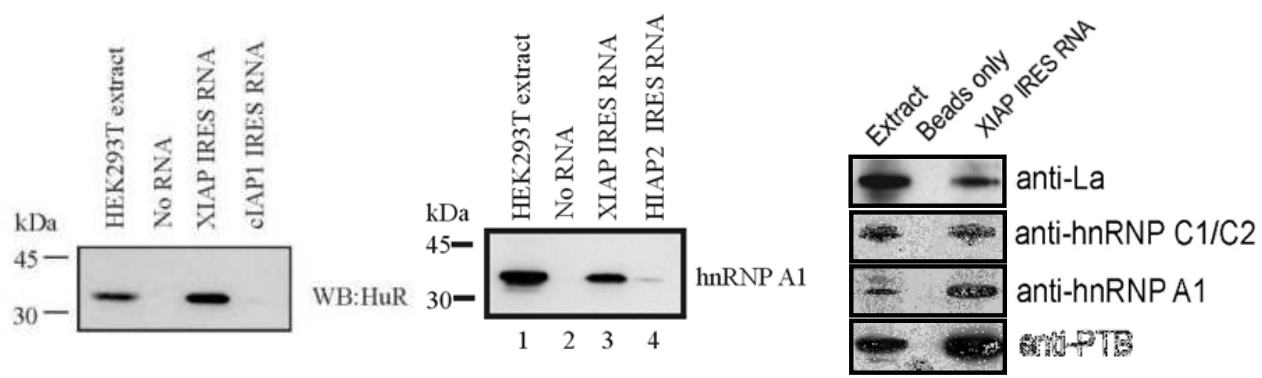

(c)

(A) Precleared HEK293T cytoplasmic lysate was incubated with avidin agarose coated with XIAP IRES RNA or avidin agarose only. Captured proteins were separated by SDS-PAGE and stained with SYPRO Ruby stain and indicated protein species were excised from the gel and subjected to mass spectrometry. (B) p37 was identified as a mixture of hnRNPA1 and HuR; underlined peptides were identified by mass spectroscopy. (C) Westernblot analysis of proteins captured on XIAP IRES RNA by avidin-biotin RNA affinity chromatography confirmed the specificity of the protein-XIAP RNA interaction. (Adapted from Baird et al., 2007; Lewis et al., 2007; Durie et al., 2011).

Fig. 4. Avidin-biotin RNA-affinity chromatography isolation of XIAP IRES binding proteins

In a similar approach, Graber et. al. used IRES containing portion of cIAP1 5' UTR (Probe I), and non-IRES portion of cIAP1 5' UTR as a control (Probe II) (Figure 5A), to isolate and identify proteins which specifically interact with the cIAP1 IRES. Four distinct proteins were isolated (Figure 5B)(Graber et al., 2010). The MALDI-TOF mass spectrometry analysis of cIAP1 IRES captured proteins identified them as RNA Helicase A (RHA), insulin-like growth factor 2 mRNA binding protein 1 (IGF2BP1), NF90 and NF45 (Figure 5C). Furthermore, Western blot analysis using antibodies against RHA, IGF2BP1, NF90 and NF45 confirmed that these proteins specifically interact with the cIAP1 IRES but not with the non-IRES portion of the cIAP1 5' UTR (Figure 5D) (Graber et al., 2010). 


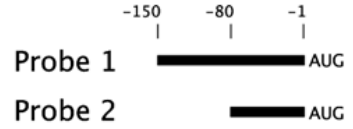

(a)

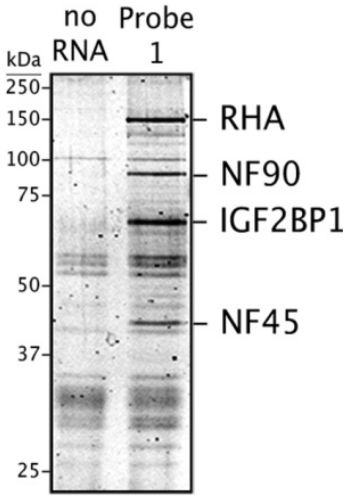

(b)
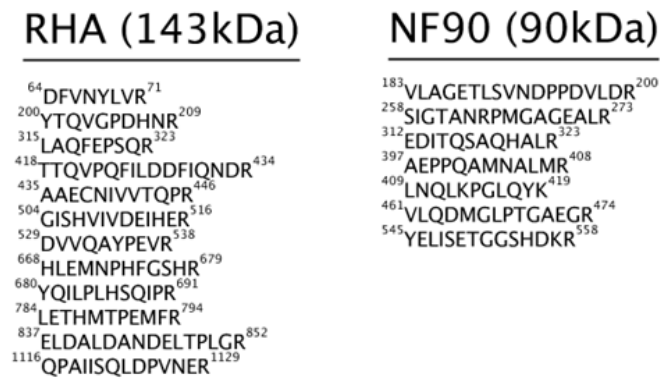

IGF2BP1 (63kDa)
${ }^{151}$ VSYIPDEQIAQGPENGR ${ }^{167}$

${ }^{191}$ QQQVDIPLR

${ }^{281}$ ILAHNNFVGR ${ }^{290}$

${ }^{53}$ MVIITGPPEAQFK ${ }^{465}$

${ }^{474}$ LKEENFFGPK

${ }^{509}$ TVNELQNLTAAEVVVPR $^{525}$

${ }^{39}$ IIGHFYASQMAQR ${ }^{551}$
NF45 (45kDa)

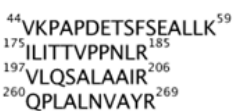

(c)

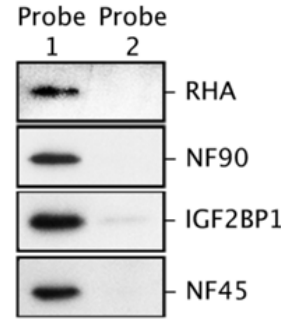

(d)

(A) Probe I: IRES containing portion of cIAP1 5' UTR; Probe II: non-IRES portion of cIAP1 5' UTR. (B) Pre-cleared HEK293T cytoplasmic lysate was incubated with avidin agarose beads coated with cIAP1 IRES RNA or avidin agarose beads only. Captured proteins were separated by SDS-PAGE and stained by SYPRO Ruby stain (C) Indicated protein species were excised from the gel and subjected to mass spectrometry. (D) Western blot analysis of proteins captured on cIAP1 IRES RNA by avidin-biotin RNA affinity chromatography confirmed the specificity of the interaction with the IRES portion of the cIAP1 5' UTR. (Adapted from Graber et al., 2010)

Fig. 5. Avidin-biotin RNA-affinity chromatography isolation of cIAP1 IRES binding proteins

\section{RNA-protein complex immunoprecipitation}

While the RNA affinity chromatography will provide information about the in vitro interaction between the protein and given RNA, the biological relevance of this interaction 
needs to be further probed in a cellular setting. The first step in this process is to validate if the RNA-protein interaction occurs in cells, and this can be done by RNA immunoprecipitation (RIP) technique. We have used the in vivo crosslinking combined with co-precipitation of RNA-protein complexes as described (Niranjanakumari et al., 2002) to demonstrate in vivo interaction between the endogenous HuR and hnRNP A1 and the endogenous XIAP mRNA. Briefly, HEK293T cells were treated with formaldehyde to cross link RNA-protein complexes. Crosslinking reaction was then stopped by adding glycine and cells were lysed by sonication. Crosslinked RNA-protein complexes were immunoprecipitated using anti-hnRNPA1 (Santa Cruz Biotechnology, Santa Cruz, CA, USA), anti-La (Chan \& Tan, 1987), anti-GAPDH (Advanced ImmunoChemicals, Long Beach, CA), anti-HuR (Santa Cruz Biotechnology) or anti-TIA-1/TIAR (clone 3E6; a gift from Dr. P. Anderson) antibodies. Following immunoprecipitation and crosslinking reversal the immunoprecipitated RNA was isolated using Trizol reagent (Invitrogen, Carlsbad, CA, USA). The isolated RNA was then reverse transcribed using an oligo $\mathrm{dT}_{18}$ primer and Superscript II (Invitrogen) to obtain cDNA. The resulting cDNA was analyzed by PCR amplification using gene specific primers and the PCR products were visualized on an ethidium bromide stained 1.5 \% (wt/vol) agarose gel (Lewis et al., 2007; Durie et al., 2011).

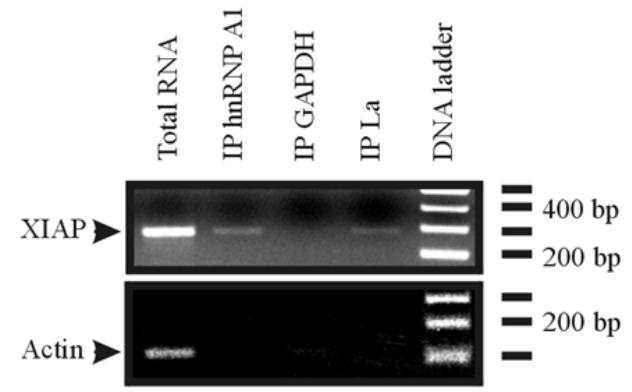

(a)

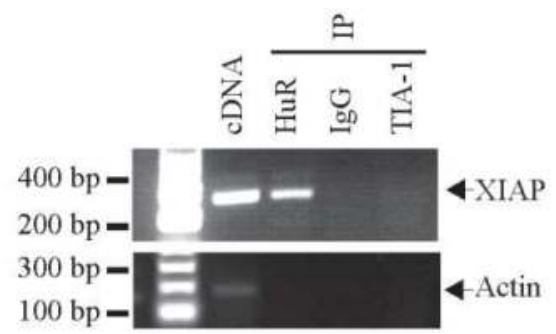

(b)

RNA-protein complexes were crosslinked using formaldehyde, isolated from cells and immunoprecipitated using antibodies against hnRNAP A1, GAPDH, La (A), HuR and TIA-1 (B). After immunoprecipation and crosslinking reversal the RNA was isolated and reverse transcribed. Genespecific primers were used for PCR amplification of the resultant CDNA, and PCR products were visualized by gel electrophoresis. (Adapted from Lewis et al., 2007; Durie et al., 2011)

Fig. 6. hnRNPA1 and HuR interact with XIAP mRNA in vivo

XIAP mRNA was isolated by immunoprecipitation with La antibody which was previously shown to interact with XIAP mRNA (Holcik \& Korneluk, 2000). Immunoprecipitation with hnRNAP A1 and HuR isolated XIAP mRNA confirmed their association with XIAP mRNA in vivo (Figure 6A; lane 2 and Figure 6B; lane 2). However, immunoprecipitation with GAPDH, TIA-1 (a known RNA binding protein) or IgG did not yield XIAP mRNA (Figure 6A; lane 3, Figure 6B; lanes 3 and 4) confirming that isolation of XIAP mRNA by immunoprecipitation with hnRNAPA1, HuR and La is specific. Importantly, $\beta$-actin mRNA (a non-specific and abundant mRNA) was not isolated by immunoprecipitation with La, hnRNP A1, GAPDH, HuR, IgG or TIA-1 antibodies. 


\section{UV crosslinking of RNA-protein complexes}

Once candidate ITAFs are isolated by the RNA affinity chromatography, their association with the IRES of interest can be further studied using UV crosslinking of RNA-protein complexes. Unlike RNA chromatography, the UV crosslinking tests the direct interaction between the purified protein and RNA. To determine if hnRNP A1 and HuR bind directly to the XIAP IRES, UV crosslinking experiment was performed using ${ }^{32} \mathrm{P}$ labelled XIAP IRES RNA probe and purified recombinant GST-hnRNP A1 and GST-HuR. GST or increasing amounts of GST-hnRNP A1 and GST-HuR were mixed with the radiolabeled RNA in a 96 well plate and UV-irradiated on ice with a 254-nm UV light source at 400,000 $\mu \mathrm{J} / \mathrm{cm}^{2}$. UVirradiated RNA-protein complexes were then treated with RNAase T1, resolved on a SDSPAGE gel and visualised by autoradiography.

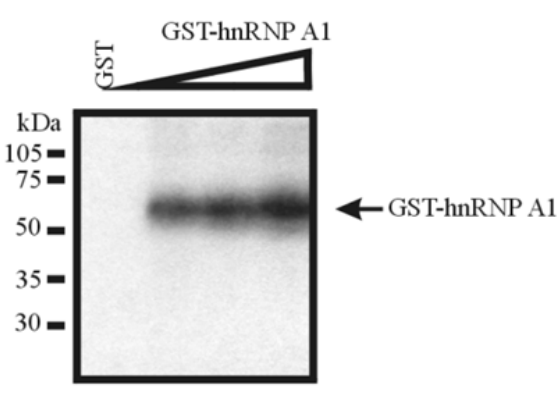

(a)

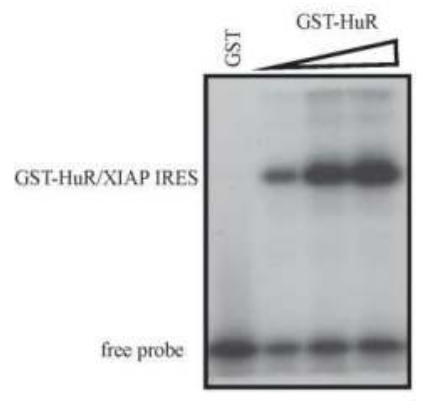

(b)

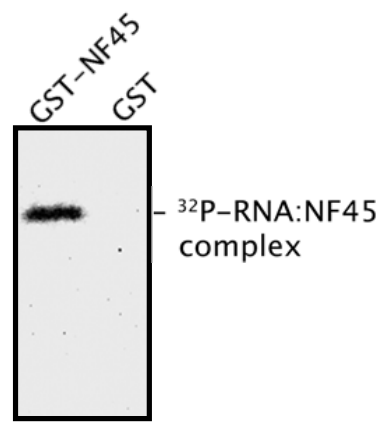

(c)

GST or increasing amounts of GST-hnRNP A1 (A) or GST-HuR (B) was mixed with radiolabeled XIAP IRES RNA probe and UV-crosslinked. It was then resolved on a SDS-PAGE gel and visualised by autoradiography. (C) GST-NF45 was mixed with radiolabeled cIAP1 IRES RNA probe and UVcrosslinked. It was then resolved on a SDS-PAGE gel and visualised by autoradiography (Adapted from Lewis et al., 2007; Graber et al., 2010; Durie et al., 2011).

Fig. 7. UV crosslinking of RNA-protein complexes

We found that GST-hnRNP A1 (Figure 7A) and GST-HuR (Figure 7B) was crosslinked to XIAP IRES RNA in a dose dependent manner which confirmed the irdirect interaction with 
XIAP IRES RNA. Similarly, GST-NF45 directly interacts with IRES portion of cIAP1 5' UTR (Figure 7C). GST did not crosslink with XIAP IRES RNA or cIAP1 IRES RNA indicating specific interactions of purified ITAFs with their respective IRES RNA.

Once the direct interaction of protein and RNA is established, it is important to define binding site(s) of the protein on the given RNA in order to understand how proteins, isolated by RNA affinity chromatography, modulate function of the given RNA. The protein binding site on the RNA can be delineated by oligonucleotide competition assay. In this approach, unlabeled oligonucleotides (competitors) are incubated with the protein of interest for $15 \mathrm{~min}$ before the addition of ${ }^{32} \mathrm{P}$ labelled target RNA. Subsequently, UV crosslinking is performed as described above and RNA-protein complexes are resolved on SDS-PAGE and visualized by autoradiography. We used oligonucleotide competition assay to map the hnRNP A1 and HuR binding sites on the XIAP IRES, and NF45 binding sites on the cIAP1 IRES. The direct interaction of XIAP IRES RNA with GST-hnRNP A1 was outcompeted by RNA oligonucleotides spanning -50 to $-25 \mathrm{nt}$ and -25 to $0 \mathrm{nt}$ of XIAP IRES RNA (Figure 8A, top panel). This suggested that hnRNP A1 bound between -50 to $0 \mathrm{nt}$ on XIAP IRES RNA, highlighted with grey box (Figure 8B). Similarly, GST-HuR binding sites were found to be between -68 to $-88 \mathrm{nt}$ and -115 to $-135 \mathrm{nt}$ of XIAP IRES RNA sequence which are located near the central core of domain I (Figure 8A, lower panel). Based on the previously defined consensus sequence (5'-NNUUNNUUU-3') (Meisner et al., 2004) we proposed that GST-HuR binds domain Ib (-126 to $-137 \mathrm{nt}$ ) of the XIAP IRES (Figure 8C) (Durie et al., 2011).

The protein binding sites on the target RNA can also be determined using slightly different approach; first the unlabelled DNA oligonucleotide competitors are hybridized to heat denatured ${ }^{32} \mathrm{P}$ labelled RNA and then it is UV crosslinked with the candidate protein, separated on SDS-PAGE and visualized by autoradiography. Using this approach we determined that AU-rich base of stem loop I (SL I) is essential for NF45 binding on cIAP1 IRES RNA (Graber et al., 2010). The NF45 binding site was further confirmed by mutating SL I of cIAP1 IRES and performing UV crosslinking experiment as described above (Graber et al., 2010).

Once the in vitro and in vivo interactions of ITAFs with the specific IRES RNA are established and the binding sites of ITAFs on specific IRES are delineated, the ability of ITAFs to modulate specific IRES mediated protein production can be studied using various cell culture techniques. These include overexpression or siRNA-mediated downregulation of candidate ITAFs followed by the determination of IRES activity using reporter constructs, and evaluation of the effect on the translation of endogenous protein by Western blot and polysome analyses. Using these techniques we have shown that cytoplasmic overexpression of FLAG-hnRNP A1 reduces endogenous XIAP expression and XIAP IRES activity (Lewis et al., 2007). Conversely, when expression of hnRNP A1 is reduced by targeting hnRNP A1 mRNA using specific siRNA, endogenous XIAP protein levels and IRES activity were significantly increased (Lewis et al., 2007). In contrast, GFP-HuR overexpression resulted in an increase of endogenous XIAP expression, whereas reduction in HuR expression by siRNA resulted in a decrease of endogenous XIAP expression and IRES activity (Durie et al., 2011). These findings suggest that hnRNP A1 negatively modulates XIAP IRES while HuR positively modulates XIAP IRES activity (Lewis et al., 2007; Durie et al., 2011). 


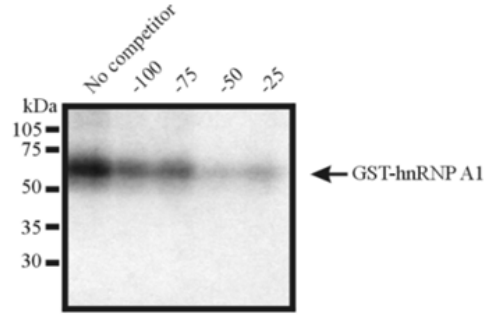

(a)

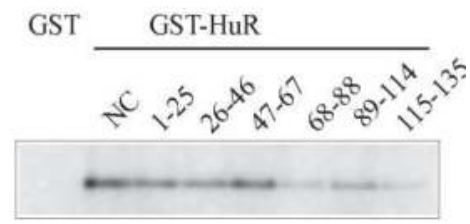

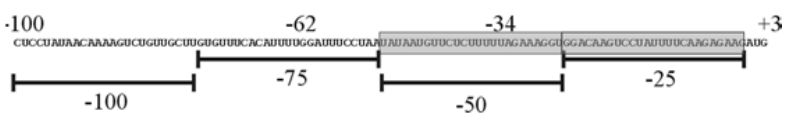

(b)

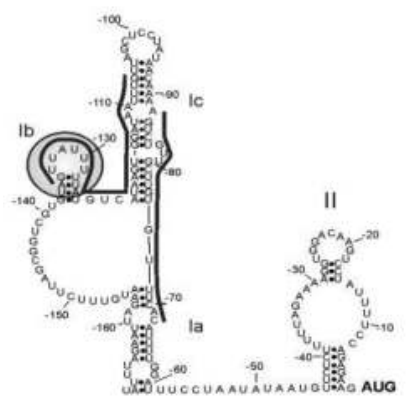

(c)

(d)

(A) ${ }^{32}$ P labelled XIAP IRES RNA was UV crosslinked with hnRNAP A1 (top) or HuR (bottom) in the absence or the presence of 100-fold excess competitor RNA oligonucleotides, separated by SDS-PAGE and visualized by autoradiography. (B) Design of RNA oligonucleotide competitors and GST-hnRNP A1 binding site, indicated by grey box. (C) XIAP IRES secondary structure (Baird et al., 2007); black lines indicate competitor oligonucleotide which outcompete GST-HuR binding. Grey circle denotes the proposed HuR binding site in domain Ib. (Adapted from Lewis et al., 2007; Durie et al., 2011)

Fig. 8. Determination of GST-hnRNP A1 and GST-HuR binding sites on XIAP IRES RNA

\section{Affinity purification of the XIAP IRES initiation complex}

Avidin-biotin RNA affinity chromatography is a powerful tool to isolate proteins associated with RNA due to tight interaction between avidin and biotin. One limitation of this approach is that $5^{\prime}$ end of the RNA is attached to the avidin matrix prior to biological complex formation. In a specific example of translation initiation, this will not allow for cap dependent ribosome recruitment. Because, the $5^{\prime}$ end of the biotinylated RNA remains in a close proximity of the solid matrix, ribosome recruitment on short IRES RNA could also be hindered. MS2-MBP based RNA affinity chromatography approach was used for the isolation of 48S initiation complex formed on hepatitis C virus (HCV) IRES RNA (Ji et al., 2004). In this approach MS2 recognition hairpins were inserted near $5^{\prime}$ end of RNA which would limit cap-dependent ribosome recruitment and initiation complex formation on RNAs which require ribosome scanning. Locker et al has described StreptoTag-based RNA affinity chromatography to isolate $48 \mathrm{~S}$ initiation complex formed on HCV IRES RNA (Locker et al., 2006). In this approach 3' endinserted StreptoTag sequence binds to sepharose coupled streptomycin with high affinity (Kd, $1 \mu \mathrm{M})$ which overcomes the above mentioned limitations. 


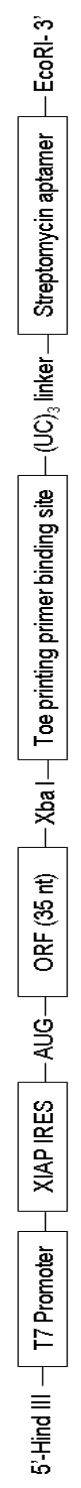

(a)
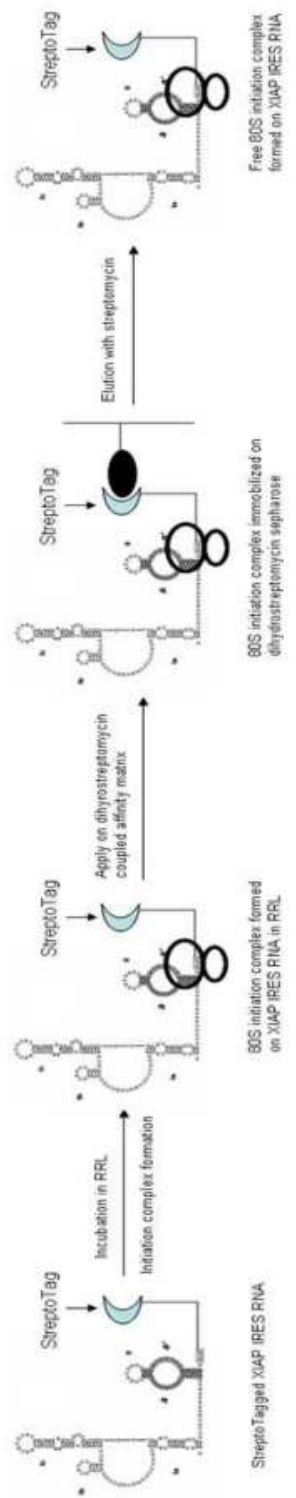

(b)

(A) Schematic diagram of DNA construct from which StreptoTagged XIAP IRES RNA was transcribed. The RNA was used for toeprinting analysis and affinity chromatography. (Adapted from Thakor \& Holcik, 2011) (B) A general scheme of isolation of initiation complex formed on StreptoTagged XIAP IRES RNA by streptomycin affinity chromatography.

Fig. 9. Streptomycin affinity chromatography 
The interaction of StreptoTagged RNA and dihydrostreptomycin is reversible and StreptoTagged RNA can be dissociated from the solid support by competition with free streptomycin. This makes streptomycin-RNA affinity chromatography a powerful and a versatile tool to isolate various functional biological complexes including initiation complexes formed on cellular mRNAs. Although we have used this approach to isolate and characterize initiation complex formed on XIAP IRES RNA, this approach can also be used to isolate other RNA associated proteins or other complexes. We transcribed StreptoTagged XIAP IRES RNA from the construct showed in Figure 9A as described (Thakor \& Holcik, 2011). Initiation complex was formed on StreptoTagged XIAP IRES RNA in RRL and applied on the dihydrostreptomycin sepharose column. After stringent washing the initiation complex formed on StreptoTagged XIAP IRES RNA was eluted using streptomycin solution (Figure 9B) and further analysed by agarose gel and toeprinting assay.

\subsection{Coupling of dihydrostreptomycin on epoxy-activated sepharose 6B}

Rehydrate epoxy-activated sepharose 6B (3g) (GE Healthcare, Glattbrugg, Switzerland) in 50 $\mathrm{ml}$ water for $30 \mathrm{~min}$ at room temperature (RT) and wash with $600 \mathrm{ml}$ water using a sintered glass funnel. Suspend epoxy-activated sepharose $6 \mathrm{~B}$ beads in $40 \mathrm{ml}$ coupling solution $(3 \mathrm{mM}$ dihydrostreptomycin in $10 \mathrm{mM} \mathrm{NaOH}$ ) and incubate on a rotator for $2 \mathrm{~h}$ at RT. Rotate the tube at $37^{\circ} \mathrm{C}$ overnight on a rotator. Decant the beads in a sintered glass funnel and wash with $200 \mathrm{ml}$ of $10 \mathrm{mM} \mathrm{NaOH}$ solution. Subsequently, suspend the beads in $6 \%$ (wt/vol) ethanolamine solution prepared in water. Rotate the tube for $10 \mathrm{~min}$ at RT on a rotator. Rotate the tube further at $42^{\circ} \mathrm{C}$ overnight in the dark. Decant the beads in the sintered glass funnel and apply three rounds of washes with $50 \mathrm{ml}$ alternating acidic buffer (0.1 M NaOAc and $0.5 \mathrm{M} \mathrm{NaCl}, \mathrm{pH} 4)$ and basic buffer (0.1 M Tris- $\mathrm{HCl}$ and $0.5 \mathrm{M} \mathrm{NaCl}, \mathrm{pH} 7.4)$. Finally, suspend the beads in $40 \mathrm{ml}$ storage buffer $\left(10 \mathrm{mMTris}^{-\mathrm{HCl}}\right.$ and $\left.10 \mathrm{mM} \mathrm{NaN}_{3}, \mathrm{pH} 7.4\right)$ and store at $4^{\circ} \mathrm{C}$ in the dark up to 3 weeks. Using a low pressure peristaltic pump pack the dihydrostreptomycin coupled beads in Poly-Prep ${ }^{\circledR}$ chromatography columns (Bio-Rad, Hercules, CA, USA).

\subsection{Dihydrostreptomycin-RNA affinity chromatography}

Incubate $4 \mathrm{ml}$ of untreated RRL with $150 \mathrm{ng} / \mathrm{ml}$ poly I:C, $1 \mathrm{mM}$ ATP, $10 \mu \mathrm{l}$ ribonuclease inhibitor (Promega) and $0.1 \mathrm{mg} / \mathrm{ml} \mathrm{CHX} \mathrm{(freezes} 80 \mathrm{~S}$ on the RNA) at $37^{\circ} \mathrm{C}$ for $20 \mathrm{~min}$. Mix $12 \mathrm{ml}$ binding buffer [20 mMTris ( $\mathrm{pH} 7.6$ ), $10 \mathrm{mM} \mathrm{MgCl}_{2}, 120 \mathrm{mM} \mathrm{KCl}, 8 \%$ sucrose, $2 \mathrm{mM}$ dithiothreitol] containing EDTA-free protease inhibitor cocktail (Roche, Mississauga, ON, Canada) and $1 \mathrm{mM}$ puromycin with RRL and incubate the reaction at $37^{\circ} \mathrm{C}$ for $10 \mathrm{~min}$. Add an in vitro transcribed, uncapped strepto-tagged XIAP IRES RNA and $1 \mathrm{mM}$ GTP into the reaction mixture. In order to achieve higher yield of XIAP IRES initiation complex, supplement the reaction with purified $40 S$ and $60 S$ from HeLa cells. Incubate the reaction further for $10 \mathrm{~min}$ at $37^{\circ} \mathrm{C}$ to form the $80 \mathrm{~S}$ initiation complex. Perform the following steps at $4^{\circ} \mathrm{C}$. While monitoring on UV recorder load $80 \mathrm{~S}$ assembly reaction onto the dihydrosteptomycin coupled beads column ( $1 \mathrm{ml} / \mathrm{min})$. Wash the column with the binding buffer $(1 \mathrm{ml} / \mathrm{min})$ until the base line is reached. Finally, elute XIAP IRES RNA initiation complex using $10 \mu \mathrm{M}$ streptomycin solution prepared in the binding buffer (Figure 10A, top panel). 


\subsection{Toeprinting analysis of XIAP IRES initiation complex isolated by dihydrostreptomycin-RNA affinity chromatography}

Dilute $5 \mu \mathrm{l}$ of the eluate in $500 \mu \mathrm{l}$ toeprinting buffer [20 mMTris- $\mathrm{HCl}$ (pH 7.6), $100 \mathrm{mM} \mathrm{KOAc}$, $2.5 \mathrm{mM} \mathrm{MG}(\mathrm{OAc})_{2}, 5 \%$ (wt/vol) sucrose, $2 \mathrm{mM}$ DTT and $0.5 \mathrm{mM}$ spermidine] and concentrate back to $40 \mu \mathrm{l}$ volume using microcon (Millipore, Billerica, MA, USA) and incubate at $30^{\circ} \mathrm{C}$ for 3 min. Subsequently, add 5 pmol of toeprinting primer (5-CTCGATATGTGCATCTGTA-3) (5' end labeled with IRDye $\left.{ }^{\mathrm{TM}} 800\right)$ and incubate reaction on ice for $10 \mathrm{~min}$. Add $1.82 \mathrm{mM}$ ATP, 1 $\mathrm{mM}$ dNTPs, $5 \mathrm{mM} \mathrm{Mg}(\mathrm{OAc})_{2}$ and $1 \mu \mathrm{l}$ of avian myeloblastosis virus reverse transcriptase (Promega) to the reaction and bring the final volume to $50 \mu l$ by toeprinting buffer. Allow primer extension to occur for $45 \mathrm{~min}$ at $30^{\circ} \mathrm{C}$. Purify the cDNA products by phenol:chloroform extraction and analyze on a standard $6 \%$ sequencing gel using a model 4200 IR2 sequence analyzer (LI-COR, Lincoln, Nebraska, USA).
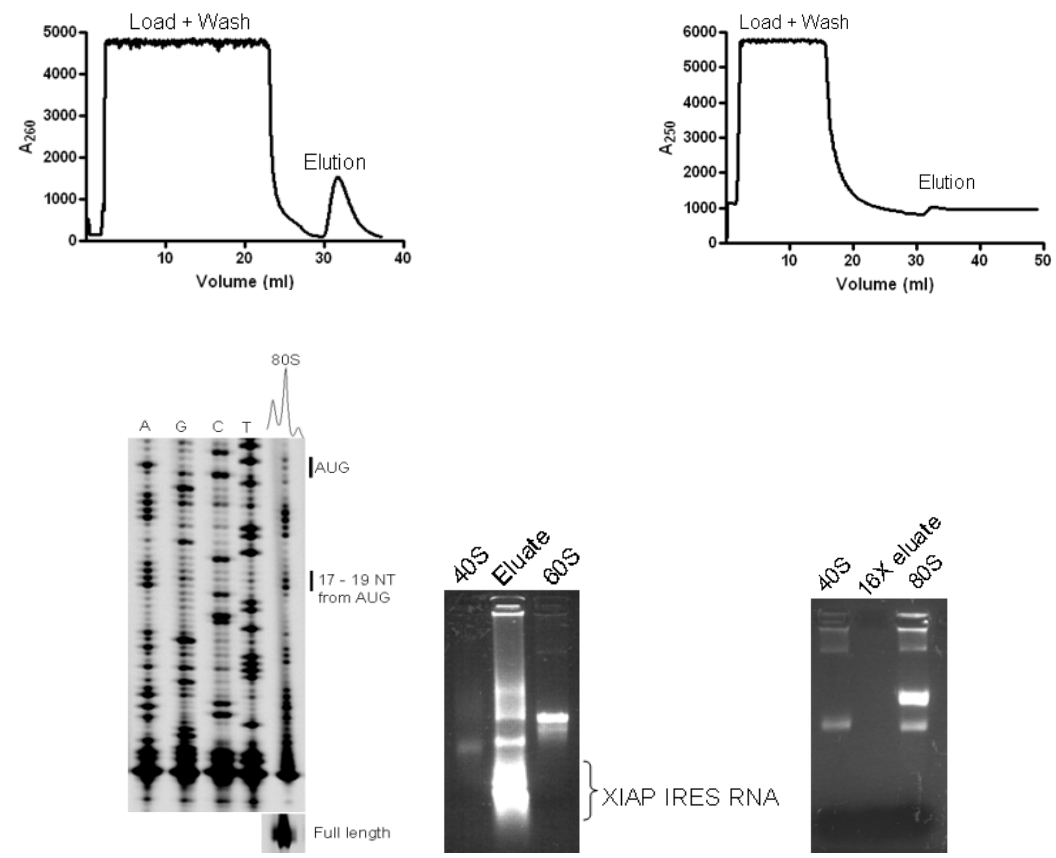

(c)

(A) RRL was supplemented with $40 \mathrm{~S}$ and $60 \mathrm{~S}$ ribosomal subunit and subsequently treated with poly I:C to induce eIF2 $\alpha$ phosphorylation. XIAP IRES RNA initiation complex was purified by streptomycinRNA affinity chromatography (top panel). Agarose gel analysis of the eluate was performed (lower panel). (B) Ribosome does not bind nonspecifically on dihydrostreptomycin coupled beads. $1 \mathrm{ml}$ RRL was mixed with $3 \mathrm{ml}$ binding buffer and loaded onto the dihydrostreptomycin column and washed with binding buffer, finally elution was carried out using streptomycin solution (top panel). Agarose gel analysis of the eluate was carried out (lower panel). (C) Eluate was further analysed by toeprinting assay. (Adapted from Thakor \& Holcik, 2011).

Fig. 10. XIAP IRES RNA forms 80 S initiation complex 


\subsection{Formation and isolation of XIAP IRES initiation complex by RNA-Streptomycin affinity chromatography}

Physiological and pathophysiological stresses induce eIF2a phosphorylation which attenuates global protein translation (Holcik \& Sonenberg, 2005). Several reports suggested that IRES mediated translation of XIAP is sustained during eIF2 $\alpha$ phosphorylation conditions (Holcik et al., 2000; Warnakulasuriyarachchi et al., 2004; Gu et al., 2009; Muaddi et al., 2010; Riley et al., 2010). We induced eIF2a phosphorylation in RRL using poly I:C (a mimic of dsRNA virus). Using primer extension inhibition assay, the so-called toeprinting assay, we have showed that XIAP IRES RNA is able to form initiation complex in eIF2a phosphorylation condition (Thakor \& Holcik, 2011). We wished to confirm the nature of XIAP IRES initiation complex formed in eIF2 $\alpha$ phosphorylation condition. To this end, we performed RNA-Streptomycin affinity chromatography in eIF2a phosphorylation condition using the Locker method (Locker et al., 2006) modified as described above.

We performed agarose gel analysis of the eluate using standard TBE gel (Figure 10A, lower panel). 40S and 60S ribosomal subunits and XIAP IRES RNA were detected by ethidium bromide staining. A mock streptomycin-RNA affinitychromatography experiment, in which XIAP IRES RNA was omitted, did not yield 80 S initiation complex (Figure 10B). These findings indicate that indeed $80 \mathrm{~S}$ initiation complex was isolated using streptomycin-RNA affinity chromatography in eIF2a phosphorylation condition. The eluate was further subjected to toeprinting analysis as described (Thakor \& Holcik, 2011). We observed toeprints +17 to $+19 \mathrm{nt}$ downstream of AUG (Figure 10C) which is a hallmark of ribosome recruitment to the AUG and stable ribosome-RNA complex formation. Depending on the distribution of fluorescence intensity $(+17<+18>+19)$ (Shirokikh et al., 2010) we further confirmed that indeed $80 S$ initiation complex was isolated which was formed on XIAP IRES RNA in eIF2a phosphorylation condition (Figure 10C). The initiation complex can be further purified by sucrose density gradient separation. Purified initiation complex can be subjected to Western blot analysis and peptide mass finger printing to confirm the presence of canonical eukaryotic initiation factors and ITAFs.

\section{Conclusion}

We have presented several alternative strategies for the isolation, purification and characterization of RNA binding proteins and complexes using RNA affinity chromatography. The avidin-biotin RNA affinity chromatography is a versatile and commonly used approach which can be used to isolate RNP complexes formed on variety of RNAs. For example, this approach can be used to isolate spliceozome complexes, RNA stabilizing or destabilizing proteins or IRES Trans Acting Factors (ITAFs). In order to illustrate its usability, we have isolated and identified XIAP and cIAP1 IRES associated proteins. Additional biochemical, molecular biology and cell culture methods were then used to demonstrate that the isolated ITAFs regulate XIAP and cIAP1 expression through IRES. Alternately, dihydrostreptomycin-RNA affinity chromatography can be employed to isolate various RNP complexes and other biologically functional complexes formed on RNA. In this approach, unlike avidin-biotin RNA affinity chromatography, RNA anchors the matrix through the $3^{\prime}$ end. Furthermore, biological complex is formed on StreptoTagged RNA prior to its attachment to the dihydrostreptomycin matrix. Therefore, StreptoTag-ed RNA containing either $5^{\prime} \mathrm{m}^{7} \mathrm{G}$ structure or an IRES element is used in the first step to form 
initiation complex. In the subsequent step, initiation complex is isolated by dihydrostreptomycin-RNA affinity chromatography. For example, we have isolated functional XIAP IRES initiation complex formed inpoly I:C treated RRL which has been further characterized.

\section{References}

Bachler M, Schroeder R, von Ahsen U. 1999. StreptoTag: a novel method for the isolation of RNA-binding proteins. Rna5:1509-1516.

Baird SD, Lewis SM, Turcotte M, Holcik M. 2007. A search for structurally similar cellular internal ribosome entry sites. Nucleic Acids Res 35:4664-4677.

Bayer EA, Wilchek M. 1990. Application of avidin-biotin technology to affinity-based separations. J Chromatogr 510:3-11.

Blagden SP, Willis AE. 2011. The biological and therapeutic relevance of mRNA translation in cancer. Nat Rev Clin Oncol 8:280-291.

Blais JD, Filipenko V, Bi M, Harding HP, Ron D, Koumenis C, Wouters BG, Bell JC. 2004. Activating transcription factor 4 is translationally regulated by hypoxic stress. Mol Cell Biol 24:7469-7482.

Braunstein S, Karpisheva K, Pola C, Goldberg J, Hochman T, Yee H, Cangiarella J, Arju R, Formenti SC, Schneider RJ. 2007. A hypoxia-controlled cap-dependent to capindependent translation switch in breast cancer. Mol Cell 28:501-512.

Caputi M, Mayeda A, Krainer AR, Zahler AM. 1999. hnRNP A/B proteins are required for inhibition of HIV-1 pre-mRNA splicing. Embo J 18:4060-4067.

Chan EK, Tan EM. 1987. Human autoantibody-reactive epitopes of SS-B/La are highly conserved in comparison with epitopes recognized by murine monoclonal antibodies. J Exp Med 166:1627-1640.

Copeland PR, Driscoll DM. 1999. Purification, redox sensitivity, and RNA binding properties of SECIS-binding protein 2, a protein involved in selenoprotein biosynthesis. J Biol Chem 274:25447-25454.

Durie D, Lewis SM, Liwak U, Kisilewicz M, Gorospe M, Holcik M. 2011. RNA-binding protein HuR mediates cytoprotection through stimulation of XIAP translation. Oncogene 30:1460-1469.

Gebauer F, Hentze MW. 2004. Molecular mechanisms of translational control. Nat Rev Mol Cell Biol 5:827-835.

Gerbasi VR, Link AJ. 2007. The myotonic dystrophy type 2 protein ZNF9 is part of an ITAF complex that promotes cap-independent translation. Mol Cell Proteomics 6:1049-1058.

Graber TE, Baird SD, Kao PN, Mathews MB, Holcik M. 2010. NF45 functions as an IRES trans-acting factor that is required for translation of cIAP1 during the unfolded protein response. Cell Death Differ 17:719-729.

Graber TE, Holcik M. 2007. Cap-independent regulation of gene expression in apoptosis. Mol Biosyst 3:825-834.

Gu L, Zhu N, Zhang H, Durden DL, Feng Y, Zhou M. 2009. Regulation of XIAP translation and induction by MDM2 following irradiation. Cancer Cell 15:363-375.

Holcik M, Gordon BW, Korneluk RG. 2003. The internal ribosome entry site-mediated translation of antiapoptotic protein XIAP is modulated by the heterogeneous nuclear ribonucleoproteins C1 and C2. Mol Cell Biol 23:280-288. 
Holcik M, Korneluk RG. 2000. Functional characterization of the X-linked inhibitor of apoptosis (XIAP) internal ribosome entry site element: role of La autoantigen in XIAP translation. Mol Cell Biol 20:4648-4657.

Holcik M, Lefebvre C, Yeh C, Chow T, Korneluk RG. 1999. A new internal-ribosome-entrysite motif potentiates XIAP-mediated cytoprotection. Nat Cell Biol 1:190-192.

Holcik M, Sonenberg N. 2005. Translational control in stress and apoptosis. Nat Rev Mol Cell Biol 6:318-327.

Holcik M, Yeh C, Korneluk RG, Chow T. 2000. Translational upregulation of X-linked inhibitor of apoptosis (XIAP) increases resistance to radiation induced cell death. Oncogene 19:4174-4177.

Hovhannisyan R, Carstens R. 2009. Affinity chromatography using 2' fluoro-substituted RNAs for detection of RNA-protein interactions in RNase-rich or RNase-treated extracts. Biotechniques 46:95-98.

Hutanu D, Remcho VT. 2007. Aptamers as molecular recognition elements in chromatographic separations. Adv Chromatogr 45:173-196.

Ji H, Fraser CS, Yu Y, Leary J, Doudna JA. 2004. Coordinated assembly of human translation initiation complexes by the hepatitis $C$ virus internal ribosome entry site RNA. Proc Natl Acad Sci USA 101:16990-16995.

Johannes G, Sarnow P. 1998. Cap-independent polysomal association of natural mRNAs encoding c-myc, BiP, and eIF4G conferred by internal ribosome entry sites. Rna 4:1500-1513.

Kaminski A, Hunt SL, Patton JG, Jackson RJ. 1995. Direct evidence that polypyrimidine tract binding protein (PTB) is essential for internal initiation of translation of encephalomyocarditis virus RNA. Rna 1:924-938.

King HA, Cobbold LC, Willis AE. 2010. The role of IRES trans-acting factors in regulating translation initiation. Biochem Soc Trans 38:1581-1586.

Komar AA, Hatzoglou M. 2011. Cellular IRES-mediated translation: the war of ITAFs in pathophysiological states. Cell Cycle 10:229-240.

Lewis SM, Veyrier A, Hosszu Ungureanu N, Bonnal S, Vagner S, Holcik M. 2007. Subcellular relocalization of a trans-acting factor regulates XIAP IRES-dependent translation. Mol Biol Cell 18:1302-1311.

Locker N, Easton LE, Lukavsky PJ. 2006. Affinity purification of eukaryotic 48 S initiation complexes. Rna 12:683-690.

Meisner NC, Hackermuller J, Uhl V, Aszodi A, Jaritz M, Auer M. 2004. mRNA openers and closers: modulating AU-rich element-controlled mRNA stability by a molecular switch in mRNA secondary structure. Chembiochem 5:1432-1447.

Mitchell SA, Spriggs KA, Bushell M, Evans JR, Stoneley M, Le Quesne JP, Spriggs RV, Willis AE. 2005. Identification of a motif that mediates polypyrimidine tract-binding protein-dependent internal ribosome entry. Genes Dev 19:1556-1571.

Muaddi H, Majumder M, Peidis P, Papadakis AI, Holcik M, Scheuner D, Kaufman RJ, Hatzoglou M, Koromilas AE. 2010. Phosphorylation of eIF2alpha at serine 51 is an important determinant of cell survival and adaptation to glucose deficiency. Mol Biol Cell 21:3220-3231.

Neupert B, Thompson NA, Meyer C, Kuhn LC. 1990. A high yield affinity purification method for specific RNA-binding proteins: isolation of the iron regulatory factor from human placenta. Nucleic Acids Res 18:51-55. 
Niranjanakumari S, Lasda E, Brazas R, Garcia-Blanco MA. 2002. Reversible cross-linking combined with immunoprecipitation to study RNA-protein interactions in vivo. Methods 26:182-190.

Pelletier J, Sonenberg N. 1988. Internal initiation of translation of eukaryotic mRNA directed by a sequence derived from poliovirus RNA. Nature 334:320-325

Peyrin E. 2009. Nucleic acid aptamer molecular recognition principles and application in liquid chromatography and capillary electrophoresis. J Sep Sci 32:1531-1536.

Ravelet C, Grosset C, Peyrin E. 2006. Liquid chromatography, electrochromatography and capillary electrophoresis applications of DNA and RNA aptamers. J Chromatogr A1117:1-10.

Riley A, Jordan LE, Holcik M. 2010. Distinct 5' UTRs regulate XIAP expression under normal growth conditions and during cellular stress. Nucleic Acids Res 38:4665-4674.

Rouault TA, Hentze MW, Haile DJ, Harford JB, Klausner RD. 1989. The iron-responsive element binding protein: a method for the affinity purification of a regulatory RNA-binding protein. Proc Natl Acad Sci USA 86:5768-5772.

Ruby SW, Goelz SE, Hostomsky Z, Abelson JN. 1990. Affinity chromatography with biotinylated RNAs. Methods Enzymol 181:97-121.

Sela-Brown A, Silver J, Brewer G, Naveh-Many T. 2000. Identification of AUF1 as a parathyroid hormone mRNA 3'-untranslated region-binding protein that determines parathyroid hormone mRNA stability. J Biol Chem 275:7424-7429.

Sharma S. 2008. Isolation of a sequence-specific RNA binding protein, polypyrimidine tract binding protein, using RNA affinity chromatography. Methods Mol Biol 488:1-8.

Shirokikh NE, Alkalaeva EZ, Vassilenko KS, Afonina ZA, Alekhina OM, Kisselev LL, Spirin AS. 2010. Quantitative analysis of ribosome-mRNA complexes at different translation stages. Nucleic Acids Res 38:e15.

Siebel CW, Kanaar R, Rio DC. 1994. Regulation of tissue-specific P-element pre-mRNA splicing requires the RNA-binding protein PSI. Genes Dev 8:1713-1725.

Silvera D, Formenti SC, Schneider RJ. 2010. Translational control in cancer. Nat Rev Cancer 10:254-266.

Silvera D, Schneider RJ. 2009. Inflammatory breast cancer cells are constitutively adapted to hypoxia. Cell Cycle 8:3091-3096.

Spriggs KA, Bushell M, Willis AE. 2010. Translational regulation of gene expression during conditions of cell stress. Mol Cell 40:228-237.

Srisawat C, Engelke DR. 2001. Streptavidin aptamers: affinity tags for the study of RNAs and ribonucleoproteins. Rna 7:632-641.

Thakor N, Holcik M. 2011. IRES-mediated translation of cellular messenger RNA operates in eIF2\{alpha\}- independent manner during stress. Nucleic Acids Res. doi 10.1093/nar/gkr701

Tombelli S, Minunni M, Mascini M. 2005. Analytical applications of aptamers. Biosens Bioelectron 20:2424-2434.

Warnakulasuriyarachchi D, Cerquozzi S, Cheung HH, Holcik M. 2004. Translational induction of the inhibitor of apoptosis protein HIAP2 during endoplasmic reticulum stress attenuates cell death and is mediated via an inducible internal ribosome entry site element. J Biol Chem 279:17148-17157.

Yaman I, Fernandez J, Liu H, Caprara M, Komar AA, Koromilas AE, Zhou L, Snider MD, Scheuner D, Kaufman RJ, Hatzoglou M. 2003. The zipper model of translational 
control: a small upstream ORF is the switch that controls structural remodeling of an mRNA leader. Cell 113:519-531.

Zhou Z, Sim J, Griffith J, Reed R. 2002. Purification and electron microscopic visualization of functional human spliceosomes. Proc Natl Acad Sci USA 99:12203-12207. 


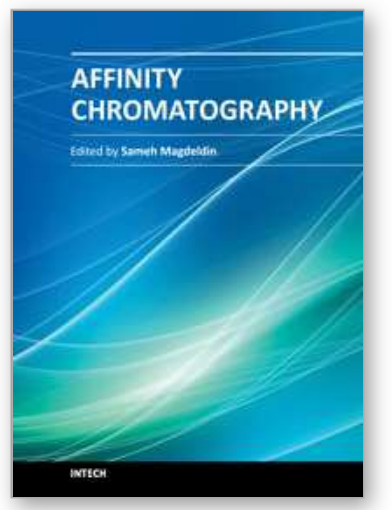

\author{
Affinity Chromatography \\ Edited by Dr. Sameh Magdeldin
}

ISBN 978-953-51-0325-7

Hard cover, 368 pages

Publisher InTech

Published online 21, March, 2012

Published in print edition March, 2012

Most will agree that one major achievement in the bio-separation techniques is affinity chromatography. This coined terminology covers a myriad of separation approaches that relies mainly on reversible adsorption of biomolecules through biospecific interactions on the ligand. Within this book, the authors tried to deliver for you simplified fundamentals of affinity chromatography together with exemplarily applications of this versatile technique. We have always been endeavor to keep the contents of the book crisp and easily comprehensive, hoping that this book will receive an overwhelming interest, deliver benefits and valuable information to the readers.

\title{
How to reference
}

In order to correctly reference this scholarly work, feel free to copy and paste the following:

Nehal Thakor and Martin Holcik (2012). RNA Affinity Chromatography, Affinity Chromatography, Dr. Sameh Magdeldin (Ed.), ISBN: 978-953-51-0325-7, InTech, Available from: http://www.intechopen.com/books/affinitychromatography/affinity-purification-and-identification-of-ires-trans-acting-factors

\section{INTECH}

open science | open minds

\section{InTech Europe}

University Campus STeP Ri

Slavka Krautzeka 83/A

51000 Rijeka, Croatia

Phone: +385 (51) 770447

Fax: +385 (51) 686166

www.intechopen.com

\section{InTech China}

Unit 405, Office Block, Hotel Equatorial Shanghai

No.65, Yan An Road (West), Shanghai, 200040, China

中国上海市延安西路65号上海国际贵都大饭店办公楼 405 单元

Phone: +86-21-62489820

Fax: +86-21-62489821 
(C) 2012 The Author(s). Licensee IntechOpen. This is an open access article distributed under the terms of the Creative Commons Attribution 3.0 License, which permits unrestricted use, distribution, and reproduction in any medium, provided the original work is properly cited. 